\title{
International Journal of Business and Management
}

\section{On Performance Audit Methods in Commercial Banks}

\author{
Xiang Li \\ School of Business, Tianjin Polytechnic University \\ Tianjin 300387, China \\ E-mail: lixiang198264@163.com
}

\begin{abstract}
Lying at the elementary stage of relevant research, China is still lacking in modern performance audit methods fit for commercial banks. This paper aims at applying data enveloping analysis in the linear programming theory as well as benchmarking management to commercial banks to effectively improve the efficiency and quality of their performance audit. In addition, the application of this method is illustrated in this paper to prove its reasonability and correctness.

Keywords: Performance audit, Commercial Banks, Performance audit methods

Performance audit is the mainstream of modern audit as well as the direction of audit development. It is of practical importance to implement performance audit in commercial banks in order to perfect their internal control system, improve their management efficiency and strengthen their duty implementation and so on. Accordingly, their performance audit should be enhanced. However, still lying at its elementary stage, the research on performance audit in commercial banks is confined to theories and short of efficient and feasible methods, which has become a major bottleneck in the development of performance audit in Chinese commercial banks. When having performance audit, only one bank can be audited at one time. This paper aims at applying modern methods to the performance audit of commercial banks to improve its efficiency, quality and level.
\end{abstract}

\section{An Introduction to Performance Audit Methods in Commercial Banks}

Here, performance audit methods refer to those means and measures utilized by the audit staff in the analysis of performance indicators to achieve their performance audit goals. In addition to general methods such as checking and inventory, some special methods in management accounting, probability theory, planning theory, queue theory, game theory, graph theory, network technology, system theory, control theory, information theory, statistics and econometrics are also employed to make up the method system of performance audit. In this paper, DEA and benchmarking management theory are the main methods employed for commercial banks' performance audit.

\subsection{Data Envelopment Analysis}

As a method of relevant effectiveness evaluation among organizations at the same level, data envelopment analysis (DEA) enables us to deal with relevant effectiveness evaluation among different input-output departments. This model based on the linear programming theory integrates multi-input indicators as well as multi-output ones into a single evaluation indicator. Each system can be viewed as a process of transformation from input to output in order to achieve the goal of a decision making unit (DMU). A system may include several units of this kind, each one of which is a kind of engagement and may be a school, a hospital, a courthouse, an air base, a bank or an enterprise. This system has the characteristics that all DMUs can be regarded as the same subjects, that is, they have the same input and output from the same perspective. Through comprehensive analysis on input and output data, DEA will result in the quantitative indicator of each DMU's comprehensive efficiency, confirm effective DMU, point out the reason and degree of other DMUs' ineffectiveness and then give some advice on performance audit to relevant departments.

The $\mathrm{C}^{2} \mathrm{R}$ model with non Archimedean infinitesimal vector serves as the main method used in this study because it is of great convenience in both judging the effectiveness of DMU and projecting ineffective DMU onto the relevant effective surface. Actually, the former is the evidence to measure the performance of banks in gaining certain amount of outputs at the expense of certain resources while the latter is the basis for giving relevant audit advice. Therefore, this $\mathrm{C}^{2} \mathrm{R}$ model is chosen as the basic model of DEA in this paper.

\subsection{Benchmarking Management Theory}

As a systematic and constant evaluation process, benchmarking management is intended to acquire information on the improvement of performance by constantly comparing a company's business process with that of those leading ones. Benchmarking management was put forward in U.S. enterprises in the beginning of 1980s to compete with the strongest opponents, to learn from the most outstanding companies' experiences and to have their reforms accordingly. Xerox 
Company is the most typical representative to conduct such management.

In this study, benchmarking management is introduced mainly to compensate for a limitation of DEA, that is, with the relevant effectiveness of DMU evaluated in DEA, a bank with effective DEA can still be chosen even when none of the samples for performance audit has satisfactory performance, which departs from the actual demands of performance audit. In order to solve it, benchmarking management is used to revise DEA in the performance audit of commercial banks in this study.

\section{The Application of the above Methods to Commercial Banks' Performance Audit}

When applying DEA to commercial banks' performance audit, we can regard the audited bank as DMU and its performance indicators as the input and output of DMU. For example, the input section may include the average staff, the average assets and the overall expenses during the period; the output section may be composed of the total deposit, the total loans as well as the total profits. Data from both sections is used to evaluate the bank's performance. Based on the characteristics of commercial banks' performance audit, we choose the $C^{2} R$ model and conduct the audit process in the following steps:

After the establishment of the $\mathrm{C}^{2} \mathrm{R}$ model, by solving the input performance indicators with linear programming, we will learn about the DEA effectiveness of DMUs. Then, for those DMUs with effective DEA, another analysis should be conducted along with the model banks to see whether they really have excellent performance. For those ineffective ones, some problems in performance audit are exposed, showing that certain input cannot produce corresponding output, not only economics output but efficiency and effect one. As a result, analysis of DEA projection should be conducted to give relevant advice.

\section{Advantages of the Employed Method}

First, this method is characterized by its objectivity since it doesn't set corresponding weights and therefore the weights of all commercial banks' performance indicators are generated automatically by the model itself, hence avoiding being influenced by subjective factors.

Second, the judgment on DMU effectiveness in this method is vital to evaluate whether a commercial bank achieves excellent performance by gaining certain amount of output at the expense of certain resources.

Third, Projection analysis on ineffective DMU in this method can help to find out ways to convert ineffective DMU to effective one, hence providing an important basis to give audit advice.

Fourth, the analysis on DMU effectiveness can also tell us whether we should increase or cut down the input of relevant resources, hence providing another important basis for audit advice.

\section{Case Study}

Based on the performance audit of 7 commercial banks in a city conducted by its audit department, this paper will elaborate on the application of the mentioned method along with its reasonability, correctness and practicability.

The audit department has collected and evaluated these banks' performance audit evidences as well as conducted relevant pre-audit investigations and risk appraisals. The specific indicators and data are shown in Table 1.

By constructing the model and having analysis with DEA, we get the results shown in Table 2.

According to a relevant theorem of DEA, when $\theta=1$, the DMU has effective DEA. As is shown in Table 1 and Table 2, A, C, D have effective DEA, hence having excellent performance, while B, E, F, G have ineffective DEA, hence leading to projection analysis. The result is shown in Table 3.

The projection analysis provides basis for advice on performance audit.

In the case of DMU with effective DEA, a comparison with the set model should be conducted. By checking on the internet and having on-the-spot interviews, the audit department collects materials on the most excellent performance and its data and sets the model unit abbreviated as $\mathrm{DMU}_{\mathrm{N}}$. It needs to be explained that the data of the model unit is not necessarily the actual data of a banks' performance indicators, but a complex of all the best performance indicators from all the banks. After eliminating disparity factors, DMU1, DMU3 and DMU5 have effective DEA. The data of the model indicators are listed in Table 4.

Then, another model is constructed to have DEA on the model data and that of the DMUs with effective DEA. The result is shown in Table 5 .

It can be concluded from the above table that A, C, D are typical banks with excellent performance with their DMUs of effective DEA proved to be effective when compared with the model.

Then, relevant advice for audit can be given based on the projection analysis and returns to scale. In this paper, advice is given to $\mathrm{B}$ as an example. 
The advice for B's performance audit is as follows: with its DMU of ineffective DEA, its performance needs to be improved and adjustments should be made to guarantee corresponding output at the expense of certain input of resources; with its average staff (26980) compared with that from the projection analysis (10928), a waste of human resources is in existence, hence calling for reduced scale of recruitment and improved staff quality and efficiency; its asset utilization rate needs to be improved with its average assets (1628.69 billion yuan) higher than that from the projection analysis (1581.76 billion yuan); its overall expenses need to be cut down properly to improve its overall performance with its overall expenses ( 72.8 billion yuan) higher than those from the projection analysis ( 70.69 billion yuan).

The conclusions from this study with the combined method of DEA and benchmarking management are basically in consistence with the actual performance of the city that year, exceeding $80 \%$, hence having great reliability.

\section{Conclusion}

This paper is focused on how to employ proper technological methods to efficiently conduct performance audit on an array of commercial banks at one time, how to apply the model of linear programming theory and some methods and models of management to commercial banks' performance audit and the advantages and disadvantages of these methods. However, it must be pointed out that the standards and methods for commercial banks' performance audit do not stay immutable, but vary with different emphasized fields and goals in different audit projects. Therefore, the case study in the paper can only be a sample for reference instead of a fixed pattern for researches of this kind.

\section{References}

Jun, Nie. (2008). Efficiency, Effect and Reengineering of Audit. Modern Management Science. 8.

Keji, Liu. (2008). An Analysis on Input-Output Elements in Performance Audit Model. China Audit. 23.

Qiang, Zheng. (2008). Exploration and Reflection on Implementing Performance Audit in Commercial Banks. Market Forum. 7.

Wei, Ji. (2005). On Performance Audit in Commercial Banks. Financial Theory and Practice. 11.

Xueping, Li. \& Zhaoquan, Wang. (2008). On the Relations between Performance Evaluation and Performance Audit. Industry Audit and Accounting. 8.

Table 1.

\begin{tabular}{|l|l|l|l|l|l|l|l|}
\hline \multirow{2}{*}{ DMU } & \multirow{2}{*}{} & Bank & \multicolumn{3}{|c|}{ Input indicators } & \multicolumn{3}{c|}{ Output indicators } \\
\cline { 3 - 8 } & & $\begin{array}{l}\text { Average } \\
\text { staff }\end{array}$ & $\begin{array}{l}\text { Average } \\
\text { assets }\end{array}$ & $\begin{array}{l}\text { Overall } \\
\text { expenses }\end{array}$ & $\begin{array}{l}\text { Total } \\
\text { deposit }\end{array}$ & Total loans & $\begin{array}{l}\text { Total } \\
\text { profit }\end{array}$ \\
\hline DMU1 & $\mathrm{A}$ & 20505 & 2412.13 & 121.44 & 2291.99 & 1825.4 & 2.77 \\
\hline DMU2 & $\mathrm{B}$ & 26980 & 1628.96 & 72.8 & 1466.18 & 1263.44 & 6.64 \\
\hline DMU3 & $\mathrm{C}$ & 746 & 184.7 & 6.13 & 161.36 & 145.1 & 0.75 \\
\hline DMU4 & $\mathrm{D}$ & 244 & 54.12 & 2.17 & 45.39 & 51.97 & 1.24 \\
\hline DMU5 & $\mathrm{E}$ & 8481 & 168.19 & 6.21 & 122.71 & 102.41 & 0.56 \\
\hline DMU6 & $\mathrm{F}$ & 1496 & 134.34 & 6.4 & 94.38 & 78.62 & 0.38 \\
\hline DMU7 & $\mathrm{G}$ & 1004 & 85.6 & 3.14 & 58.33 & 47.35 & 0.36 \\
\hline
\end{tabular}

Table 2.

\begin{tabular}{|l|l|l|l|}
\hline DMU & Bank & Efficiency value $\theta$ & Effectiveness of DEA \\
\hline DMU1 & A & 1.000 & Effective DEA \\
\hline DMU2 & B & 0.971 & Ineffective DEA \\
\hline DMU3 & C & 1.000 & Effective DEA \\
\hline DMU4 & D & 1.000 & Effective DEA \\
\hline DMU5 & E & 0.803 & Ineffective DEA \\
\hline DMU6 & F & 0.751 & Ineffective DEA \\
\hline DMU7 & G & 0.758 & Ineffective DEA \\
\hline
\end{tabular}


Table 3 .

\begin{tabular}{|l|l|l|l|l|l|}
\hline DMU & University & & $\begin{array}{l}\text { Average } \\
\text { number } \\
\text { people }\end{array}$ & Average assets & $\begin{array}{l}\text { Overall } \\
\text { expenses }\end{array}$ \\
\hline DMU2 & \multirow{2}{*}{ B } & Before change & 26980.00 & 1628.69 & 72.80 \\
\cline { 3 - 6 } & & After changes & 10928.00 & 1581.76 & 70.69 \\
\cline { 3 - 6 } & & D-value & 16052.00 & 46.93 & 2.11 \\
\hline \multirow{2}{*}{ DMU5 } & \multirow{2}{*}{ E } & Before change & 8481.00 & 168.19 & 6.21 \\
\hline & & After changes & 688.00 & 134.99 & 4.98 \\
\cline { 3 - 6 } & & D-value & 7793.00 & 33.2 & 1.23 \\
\hline \multirow{2}{*}{ DMU6 } & \multirow{2}{*}{$\mathrm{G}$} & Before change & 1496.00 & 134.34 & 6.40 \\
\cline { 3 - 6 } & & After changes & 775.00 & 100.89 & 4.80 \\
\cline { 3 - 6 } & & D-value & 721.00 & 33.45 & 1.6 \\
\hline & & Before change & 1004.00 & 85.60 & 3.14 \\
\hline & & After changes & 319.00 & 64.87 & 2.38 \\
\hline & & D-value & 685.00 & 20.73 & 0.76 \\
\hline
\end{tabular}

Table 4.

\begin{tabular}{|l|l|l|l|l|l|l|l|}
\hline DMU & \multirow{2}{*}{ Bank } & \multicolumn{3}{|c|}{ Input indicators } & \multicolumn{3}{c|}{ Output indicators } \\
\cline { 3 - 8 } & & $\begin{array}{l}\text { Average } \\
\text { staff }\end{array}$ & $\begin{array}{l}\text { Average } \\
\text { assets }\end{array}$ & $\begin{array}{l}\text { Overall } \\
\text { expenses }\end{array}$ & $\begin{array}{l}\text { Total } \\
\text { deposit }\end{array}$ & Total loans & $\begin{array}{l}\text { Total } \\
\text { profit }\end{array}$ \\
\hline $\begin{array}{l}\text { DMU } \\
\text { N }\end{array}$ & Model bank & 1404 & 243.67 & 9.38 & 228.77 & 189.1 & 0.34 \\
\hline
\end{tabular}

Table 5.

\begin{tabular}{|l|l|l|l|}
\hline DMU & Bank & $\theta$ & Effectiveness of DEA \\
\hline Model unit & Model bank & 1.000 & Effective DEA \\
\hline DMU1 & A & 1.000 & Effective DEA \\
\hline DMU3 & C & 1.000 & Effective DEA \\
\hline DMU4 & E & 1.000 & Effective DEA \\
\hline
\end{tabular}

